\title{
Cardiovascular Physiology
}

National Cancer Institute

\section{Source}

National Cancer Institute. Cardiovascular Physiology. NCI Thesaurus. Code C16385.

Study of the functions and activities of the cardiovascular system as a whole or of any of its parts. 